\title{
Estimation of Gender by Using Decision Tree, a Machine Learning Algorithm, With Patellar Measurements Obtained From MDCT Images
}

\author{
MDBT Görüntülerinden Elde Edilen Patellar Ölçümler İle Bir Makine \\ Öğrenme Algoritması Olan Karar Ağacı Kullanılarak Cinsiyet Tahmini
}

\author{
(D)Serkan Oner ${ }^{1}$, (D)Muhammed Kamil Turan², (D)Zulal Oner \\ 'Department of Radiology, Faculty of Medicine, Karabuk University, Karabuk, Turkey \\ 2Department of Medical Biology, Faculty of Medicine, Karabuk University, Karabuk, Turkey \\ ${ }^{3}$ Department of Anatomy, Faculty of Medicine, Karabuk University, Karabuk, Turkey
}

Copyright $@ 2021$ by authors and Medical Records Publishing Inc.

\begin{abstract}
Aim: The present study aimed to analyze whether gender could be determined with the decision tree (DT) method, a machine learning algorithm, based on patellar multidetector computed tomography (MDCT) image measurements.

Material and Methods: The study was conducted on 219 male and 131 female MDCT images. The patellar anteroposterior (Ap), craniocaudal (Cc), transverse (Trv) length and volume ( Vol), adjusted on the orthogonal plane by the radiologist, were calculated. In patellar length measurements, initially linear discriminant outliers were detected to clear the data for gender prediction. Accuracy (Acc), Sensitivity (Sen), Specificity (Spe), F1-Score (F1) and Matthew's Correlation Coefficient (Mcc) criteria were taken as the performance criteria for DT.

Results: It was determined that male Ap, Trv, Cc, and Vol values were higher when compared to the female values and there was a

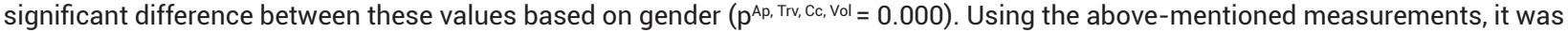
calculated that the prediction rate for male individuals was $98.2 \%$ and for female individuals, it was $98.4 \%$.

Conclusion: DT analysis based on patella morphometry provided a simple, adequate and highly accurate approach for gender estimation. Furthermore, it was determined that it would provide an advantage for researchers in gender prediction using only branching and cut-off values on the tree structure without the need to use a computer.

Keywords: Decision tree; gender estimation; linear discriminant analysis; patella; multidetector computed tomography; osteometry

$\mathrm{Oz}$

Amaç: Bu çalışmanın amacı, patellanın multi-detektör bilgisayarlı tomografı (MDBT) görüntüleri üzerinden yapılan ölçümlerinden, bir makine öğrenmesi olan karar ağacı (KA) metodu kullanılarak cinsiyet belirlenmesi yapılıp yapılamayacağını ortaya koymaktır.

Materyal ve Metod: Çalışmaya 219 erkek ve 131 kadın bireye ait MDBT görüntüleri dahil edilmiştir. Radyolog tarafından, ortogonal düzleme getirilen patellanın anteroposterior (Ap), kraniokaudal $(\mathrm{Kk})$, transvers (Trv) uzunlukları ölçüm aracıyla ölçülmüş ve volümleri (Vol) hesaplanmıştır. Patellar uzunluk ölçümlerine öncelikle lineer ayırt edici aykırı değer tespiti yapılmış, bu sayede cinsiyeti tahmin için veriler temizlenmiştir. KA için performans kriteri olarak karışıklık matrisi üzerinden hesaplanan Doğruluk, Sensitivite, Spesifite, F1-Skoru ve Matthew Korelasyon Katsayısı ölçütleri kullanılmıştır.

Bulgular. Erkeklerin Ap, Trv, Kk ve Vol değerleri kadınlardan daha yüksek olarak bulunmuş ve aralarında anlamlı fark tespit edilmiştir ( $\mathrm{p}^{\mathrm{Ap}}$,

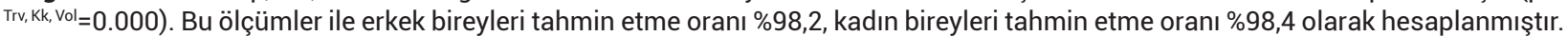
Sonuç: Patella morfometrisine dayalı KA analizi, cinsiyet tahmini için basit, yeterli ve oldukça doğru bir yaklaşım sağlamıştır. Ayrıca araştırmacılara herhangi bir bilgisayara ihtiyaç duymadan sadece ağaç yapısı üzerinde dallanmaları ve cut-off değerleri kullanarak cinsiyet tahmini yapmak konusunda avantaj sağlamaktadır.
\end{abstract}

Anahtar Kelimeler. Karar ağacl; cinsiyet tahmini; lineer diskriminant analizi; patella; multi-dedektör bilgisayarlı tomografi; osteometri

Geliş Tarihi / Received: 19.12.2020 Kabul Tarihi / Accepted: 18.01.2021

Sorumlu Yazar /Corresponding Author. Serkan Oner, Department of Radiology, Faculty of Medicine, Karabuk

University, Karabuk, Turkey, E-mail: serkanoner@karabuk.edu.tr 


\section{INTRODUCTION}

Forensic anthropology requires accurate and reliable methodologies to determine the gender of human remains without a known gender (1). Thus far, gender identification has been conducted on skeletal remains to identify individuals in forensic sciences and to analyze populations in archaeology (2). When the entire skeleton is available for analysis, gender prediction is more reliable; however, in forensic cases, human skeletal remains are often partial or damaged (3). In a forensic case where all bones are not available, differential function equations should be derived using various bones to estimate the gender (2).

Generally, morphological and metric methods are used to estimate gender with skeletal remains. The morphological method includes observation of gender-specific properties of the bones, however accurate results are obtained only when the observer has sufficient experience. On the other hand, the metric method is based on measurements and statistical techniques that do not require expertise and could be repeated to confirm the results (2). Physical anthropology has conventionally used both qualitative and quantitative strategies to predict gender with skeletal remains, however, due to its variable nature, the osteometry has generally been considered a more reliable approach (4).

The skull, pelvis and long bones are often absent or disintegrated, thus gender prediction should be attempted with other skeleton parts. However, the accuracy of gender prediction using skeletal elements depends on the degree of sexual dimorphism exhibited by the skeleton (3). Patella is the largest sesamoid bone in the human body. It is articulated with the femur and covers and protects the anterior knee joint surface. Patella develops in quadriceps femoris tendon and ossifies from a single center (5). It has a triangular shape and front and rear surfaces, three sides and a top. Patella is a strong bone without a significant morphological feature for the determination of gender and significant differences based on race. However, as a sesamoid bone formed within the quadriceps femoris tendon, it is resistant to postmortem and taphonomy variations and therefore valuable in the prediction of gender with unknown human remains $(2,5)$.

The decision tree (DT) algorithm is one of the frequently used data mining classification algorithms. It is used to make a decision based on pre-determined parameters. It generates a set of rules for the decision (6). The decision tree algorithm is easy to understand and interpret, it can be easily processed without the need for missing values, it is easy to process heavy skewed data, and it can tolerate outlier values to some extent (7).

The present study aimed to analysis whether gender could be determined with DT, a machine learning algorithm, based on patella measurements conducted using multidetector computed tomography (MDCT) images.

\section{MATERIAL AND METHODS}

\section{Study population and analysis}

The present study was approved by the Ethics Committee for Non-Interventional Clinical Trials with protocol no. $6 / 22$. CT images of the lower extremities that included the patella taken for various indications between January 2015 and May 2019 were reviewed. Images obtained from 219 male and 131 female subjects were included in the study without right-left discrimination. Subjects with significant bone deformity and a history of surgery were excluded from the study. All obtained CT images were taken with a 16-slice MDCT scanner (Aquilion 16; Toshiba Medical Systems, Tokyo, Japan). The cross-sectional thickness was $1 \mathrm{~mm}$ in all images.

All measurements were conducted by an experienced radiologist in a workstation (Vitrea v6.1, Vital Images, Plymouth, MN, USA). The images in the axial plane were analyzed with two- and three-dimensional reconstructions (Maximum Intensity Projection-MIP, Volume Rendering) in the bone window. Images that focused on the patella were adjusted to the orthogonal plane in three planes. Anteroposterior (Ap), craniocaudal (Cc), and transverse (Trv) length of the patella were measured with the measurement device after the cross-sectional thickness was maximized. The entire patella region was stained with the Volume (Vol) measurement instrument. The accuracy of the stained patella boundaries was checked with the field lines and required corrections were made and finally, the patella volume was calculated (Figure 1). All measurements were conducted in 3 replicates. Since the images of certain individuals included bilateral patella, a total of 6 measurements were taken in this group. For the DT model to be able to encounter the maximal variation the statistical differences that could potentially exist between the measurements at the different time were ignored.

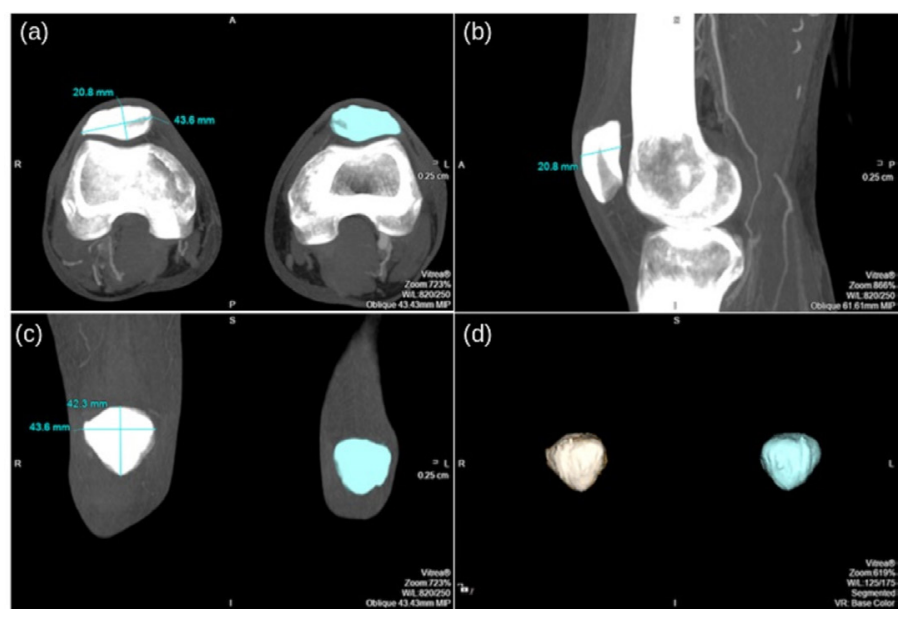

Figure 1. Patellar measurements. (a) Axial, (b) Sagital, (c) Coronal, (d) 3D image

In order to determine the gender based on patellar measurements, a framework structure was developed with Python programming language. Python programming language was selected since its structure is adequate 
for scientific calculation, due to the simplicity of its syntax structure, and since it is an open development platform independent of the development environment (8). Statistical calculations were conducted with Stats models with a Python programming language statistical framework and Pandas with a data structure framework $(9,10)$. Also, scikit-learn framework was used for the DT algorithm. This framework was selected since it is an open source easy to use software with a commercial BSD license and has full compatibility with popular frameworks such as Numpy, Scipy and Matplotlib $(11,12)$.

\section{Data structure}

The data structure used for patellar measurements was the text format. This format is designed as a flat file that included comma-separated values (csv). The Pandas framework was used to read the measurements and convert them into structured data. Measurements conducted on the structured data structure were separated into Id, Name, Age, Gender, Ap, Trv, Cc, Vol, Out3 fields. Where, Id is a unique number used for measurement. Out3 parameter was denoted with 1 for males and 0 for females and used for classification.

Data cleaning, training and test sets, and performance criteria

Initially, patellar length measurements were conducted with linear discriminant outlier detection. Thus, data that would be used for gender prediction were cleared of outliers (13). The first $80 \%$ of the patellar length measurements were set as the training set and the remaining $20 \%$ were set as the test set. Training and test procedures were conducted using the selected training set by randomizing the patella data set for each procedure and the test was conducted with the test set that the DT model was never exposed to. The model developed for more realistic performance criteria, was tested on 500 different test sets. Thus, the probability that each data line was a training set element and that each data line was a test set element were increased. Furthermore, the distribution of performance criteria was determined as a result of repeated training and test procedures. The DT performance criteria included Accuracy (Acc), Sensitivity (Sen), Specificity (Spe), F1-Score (F1) and Mathew's Correlation Coefficient (Mcc) criteria, calculated with the confusion matrix. Performance criteria were calculated with the Equation- 1 set.

$$
\begin{aligned}
A c c & =\frac{T P}{T P+F P+F N+T N} \\
\text { Sen } & =\frac{T P}{T P+F N} \\
\text { Spe } & =\frac{T N}{T N+F P} \\
M c c & =\frac{T P \cdot T N-F P \cdot F N}{\sqrt{(T P+F P) \cdot(T P+F N) \cdot(T N+F P) \cdot(T N+F N)}} \\
F_{1} & =2 \frac{\text { Sen.Spe }}{\text { Sen }+ \text { Pre }}
\end{aligned}
$$

Eq. (1) DT performance criteria, Accuracy (Acc), Sensitivity (Sen), Specificity (Spe), F1-Score (F1) and Mathew's Correlation Coefficient (Mcc) calculated with the confusion matrix.

\section{Decision tree}

Decision trees are an algorithm that allows writing various rules between the existing data and the classes of data. In decision trees, the parameters are represented by branching and parent nodes. The results are the tree leaves and nodes (14). In order to provide an acceptable outcome success rate based on parameter values, a set of rules is written (the acceptable success rate is accepted as 0.85 in the present study). Thus, several clusters that include data and various classes are divided into smaller clusters and classified. The advantages of the method include is ease of use, ability to present clearly visualized rules, ability to develop rules to classify the dataset, ability to classify with less data, and ability to classify both numerical and semantic expressions. Its disadvantages include the fact that tree structures that best describe the data may be extremely complex in certain cases and they are not suitable to work with missing or lost data (15). In the present study, DT was used to predict gender based on 4 patellar parameters and to write a set of rules to determine gender based on patellar measurements. The models required for DT were developed and tested with the scikit-learn framework.

\section{RESULTS}

The reported study findings included comparative results obtained before and after outlier removal with linear discriminant analysis (LDA).

\section{Main statistical findings before the outliers were removed with LDA}

A total of 1166 measurements were conducted on images obtained from 219 males and 1007 measurements were conducted on images obtained from 131 females. Anderson Darling normality test was used to test whether Age, Ap, Trv, Cc, and Vol values exhibited normal distribution. The test findings demonstrated that Age, Ap, Trv, Cc and Vol values did not exhibit a normal distribution (for males: $\mathrm{p}^{\mathrm{Ap}}=0.008, \mathrm{p}^{\mathrm{Tr}, \mathrm{Cc}, \mathrm{Vol}}=0.000$, for females: $\mathrm{p}^{\mathrm{Ap}}$ $=0.0007$ for women, $\mathrm{p}^{\mathrm{Trv}}=0.0000, \mathrm{p}^{\mathrm{cc}}=0.0002, \mathrm{p}^{\mathrm{V} \mathrm{o}} \mathrm{l}=$ 0.0023). Mann-Whitney $U$ test was used to determine whether there was a difference between the values since they did not exhibit a normal distribution. The median male age was $64(\min 18, \max 91)$, the median female age was 60 ( $\min 18, \max 91)$. There was no significant difference between the ages of male and female subjects $(p=0.011)$. It was found that male Ap, Trv, Cc, and Vol values were higher when compared to females and there were significant differences based on gender $\left(\mathrm{p}^{\mathrm{Ap}, \mathrm{Trv}, \mathrm{Cc}, \mathrm{Vol}}\right.$ 
$=0.000)$. The distribution of patellar Ap, Trv, Cc and Vol measurements for males and females are presented in Table 1.

\begin{tabular}{|c|c|c|}
\hline & Male & Female \\
\hline Parameters & Median (min-max) & Median (min-max) \\
\hline Ap & $24.70(20.20-31.80)$ & $23.00(17.80-28.20)$ \\
\hline Trv & $47.70(37.10-57.20)$ & $43.10(34.70-49.50)$ \\
\hline Cc & $45.90(37.70-56.70)$ & $41.75(31.90-50.50)$ \\
\hline Vol & $23.47(14.32-39.42)$ & $17.90(8.91-24.62)$ \\
\hline
\end{tabular}

Main statistical findings after the outliers were removed with LDA

After the outlier removal conducted with LDA, 179 males and 119 females were included in the study. A total of 822 measurements obtained from 179 males and 849 measurements obtained from 119 females were included. The distribution of the ages of male and female subjects did not exhibit normal distribution ( $\mathrm{p}^{\text {Male }}=0.0000, \mathrm{p}^{\text {Female }}$ $=0.0000)$. The median male age was $63(\min 18, \max$ $91)$ and the median female age was $57(\min 18, \max 91)$. It was observed that all measurements for males and females did not exhibit normal distribution (for males: $\mathrm{p}^{\mathrm{Ap}}$ $=0.0234, p^{T r v}, \mathrm{Vol}, \mathrm{Cc}=0.000$; for females: $\mathrm{p}^{\mathrm{Ap}}=0.0003, \mathrm{p}^{\mathrm{Tr}, \mathrm{Vol},}$ $\mathrm{cc}^{\mathrm{a}}=0.000$ ). All measurements conducted on males were higher when compared to female measurements and there was a statistically significant difference between these

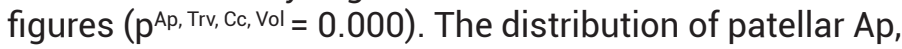

Trv, Cc and Vol measurements for males and females is presented in Table 2.

Table 2. Distribution of patellar measurements based on gender after outliers were removed with LDA (min: Minimum, max: Maximum, Ap: Anterior to Posterior length, Trv: Transversal length, Cc: Cranio-Caudal length, Vol: Volume)

\section{Male}

Parameters

Ap

Trv

Cc

Vol

$$
\begin{aligned}
& \text { Median (min-max) } \\
& 25.20(20.50-31.80) \\
& 48.90(43.80-58.20) \\
& 46.80(38.10-56.70) \\
& 25.04(18.52-39.42)
\end{aligned}
$$

Female

$$
\text { Median (min-max) }
$$$$
22.80(17.80-28.20)
$$$$
42.10(34.70-47.60)
$$$$
40.97(31.90-50.50)
$$$$
16.98(8.91-22.25)
$$

It was calculated that there were significant statistical differences between the Age, Ap, Trv, Cc and Vol values before and after outlier removal was conducted with LDA

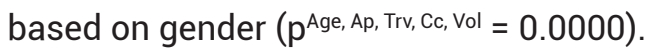

\section{Decision tree}

DT and gender prediction findings are presented in two sections; the first section includes data obtained before the outlier removal with LDA and the second section includes the data after the outlier removal with LDA.

\section{Findings obtained before the outlier removal with LDA}

Various DT models with a max. depth of 3,4,5 and unlimited were tested. In none of these models, the total Acc value was greater than 0.82 (maximum depth of tree of 3,4 and 5 ). In the present study, since the Acc was accepted as over 0.85 , the pre-LDA dataset was not considered successful. The performance criteria are presented in Table 3.

Table 3. The performance criteria findings for the case where various maximum depth of tree was used in the DT method (Acc: Accuracy, Spe: Specificity, Sen: Sensitivity, F1: F1-Score, Mcc: Matthew's correlation coefficient)

\section{Performance}

Maximum depth of tree

$\begin{array}{lcccc} & 3 & 4 & 5 & \text { None } \\ \text { Acc } & 0.810(0.729-0.850) & 0.811(0.722-0.854) & 0.811(0.765-0.854) & \\ & & & 0.846 \pm 0.013 \\ \text { Spe } & 0.758(0.570-0.911) & 0.804(0.580-0.894) & 0.600-0.901) & 0.843 \pm 0.024 \\ \text { Sen } & 0.841(0.579-0.971) & 0.825(0.581-0.971) & 0.696-0.957) & 0.849 \pm 0.021 \\ \text { F1 } & 0.804(0.708-0.850) & 0.808(0.704-0.853) & 0.809(0.726-0.854) \\ \text { Mcc } & 0.623(0.487-0.699) & 0.624(0.489-0.709) & 0.625 \pm 0.026\end{array}$


Maximum dept of tree was set to unlimited to prevent the limit on the depth of the tree. However, it is practically impossible to derive a set of rules from the resulting tree. Therefore, the maximum depth of tree with the highest Mcc value was accepted as 4 and called that the DT general solution model.

The DT general solution model was trained 500 times with different training sets selected from the dataset, tested 500 times with various test sets, and the resulting distribution of the performance criteria are presented in Figure. 2.

\section{Findings obtained after the outlier removal with LDA}

Various DT models with a max. depth of $3,4,5$ and unlimited were tested. In all models, the total Acc value was greater than 0.97 and the models were accepted as successful. The performance criteria are presented in Table 4.
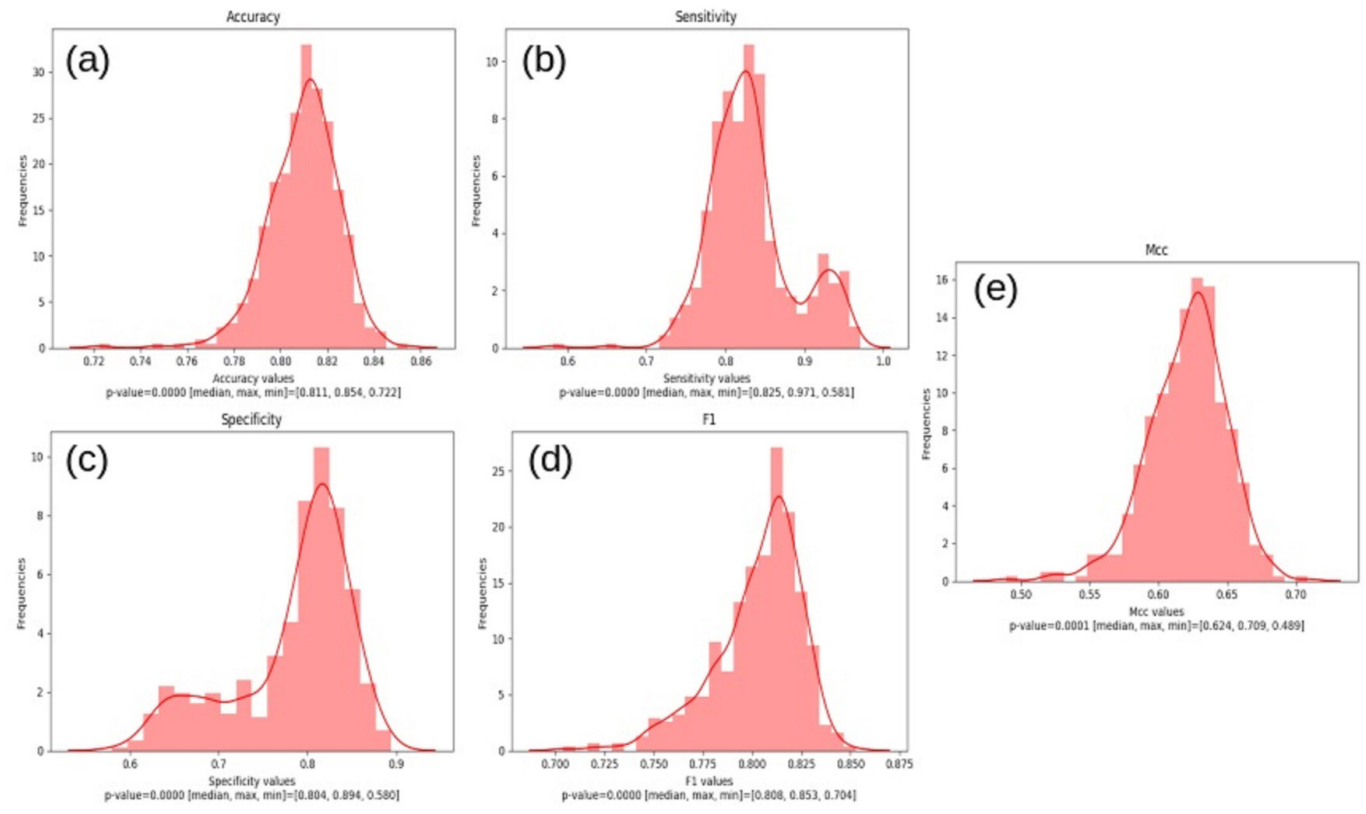

Figure 2. Distribution of performance criteria before LDA outlier removal, (a) Acc distribution, (b) Sen distribution, (c) Spe distribution, (d) F1 distribution, (e) Mcc distribution. Acc: Accuracy, Spe: Specificity, Sen: Sensitivity, F1: F1-Score, Mcc: Matthew's correlation coefficient.

Table 4. Performance criteria findings when DT method with different maximum depth of trees was used (Acc: Accuracy, Spe: Specificity, Sen: Sensitivity, F1: F1-Score, Mcc: Matthew's correlation coefficient)

\section{Performance}

Criteria

Acc

Spe

Sen

F1

Mcc
$0.972(0.940-0.990)$

$0.975(0.898-1.000)$

$0.973(0.914-0.996)$

$0.972(0.940-0.990)$

$0.944(0.881-0.980)$
Maximum depth of tree

None

$0.982(0.962-0.994)$

$0.984(0.964-0.998)$

$0.984(0.966-0.998)$

$0.984(0.946-1.000)$

$0.985(0.938-1.000)$

$0.987(0.952-1.000)$

$0.980(0.939-1.000)$

$0.984(0.948-1.000)$

$0.984(0.951-1.000)$

$0.982(0.961-0.994)$

$0.984(0.965-0.998)$

$0.984(0.966-0.998)$

$0.964(0.925-0.988)$

$0.968(0.928-0.996)$

$0.968(0.933-0.996)$
Based on the findings presented in Table 4, the model where the maximum depth of tree was assigned as 4 was selected as the DT general solution model based on the fact that the set of rules could be easily created from this tree structure. The DT general solution model was trained
500 times with different training sets selected from the dataset and tested 500 times with various test sets and the resulting distribution of the performance criteria are presented in Fig. 3. 

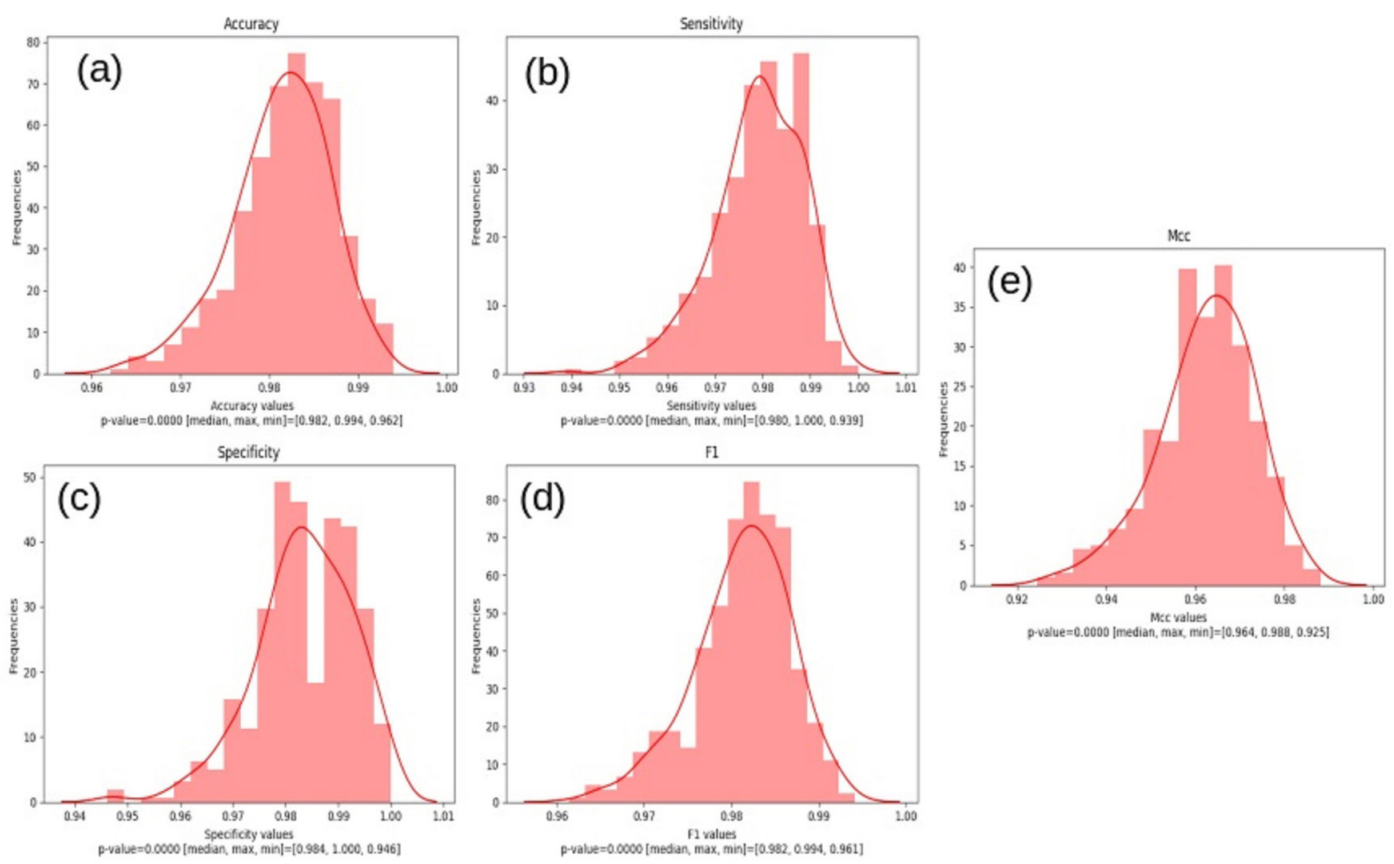

Figure 3. Distribution of performance criteria after LDA outlier removal (a) Acc distribution, (b) Sen distribution, (c) Spe distribution, (d) F1 distribution, (e) Mcc distribution. Acc: Accuracy, Spe: Specificity, Sen: Sensitivity, F1: F1-Score, Mcc: Matthew's correlation coefficient.

The confusion matrix obtained by running the DT general solution model on randomly selected test sets on each run is presented in Fig. 4. High Spe and Sen values were noted in the test set for both genders. In the predictions for males, the Sen value was calculated as 0.01 percent higher when compared to the predictions conducted with female measurements. The decision tree obtained after the LDA was conducted is presented in Fig. 5.

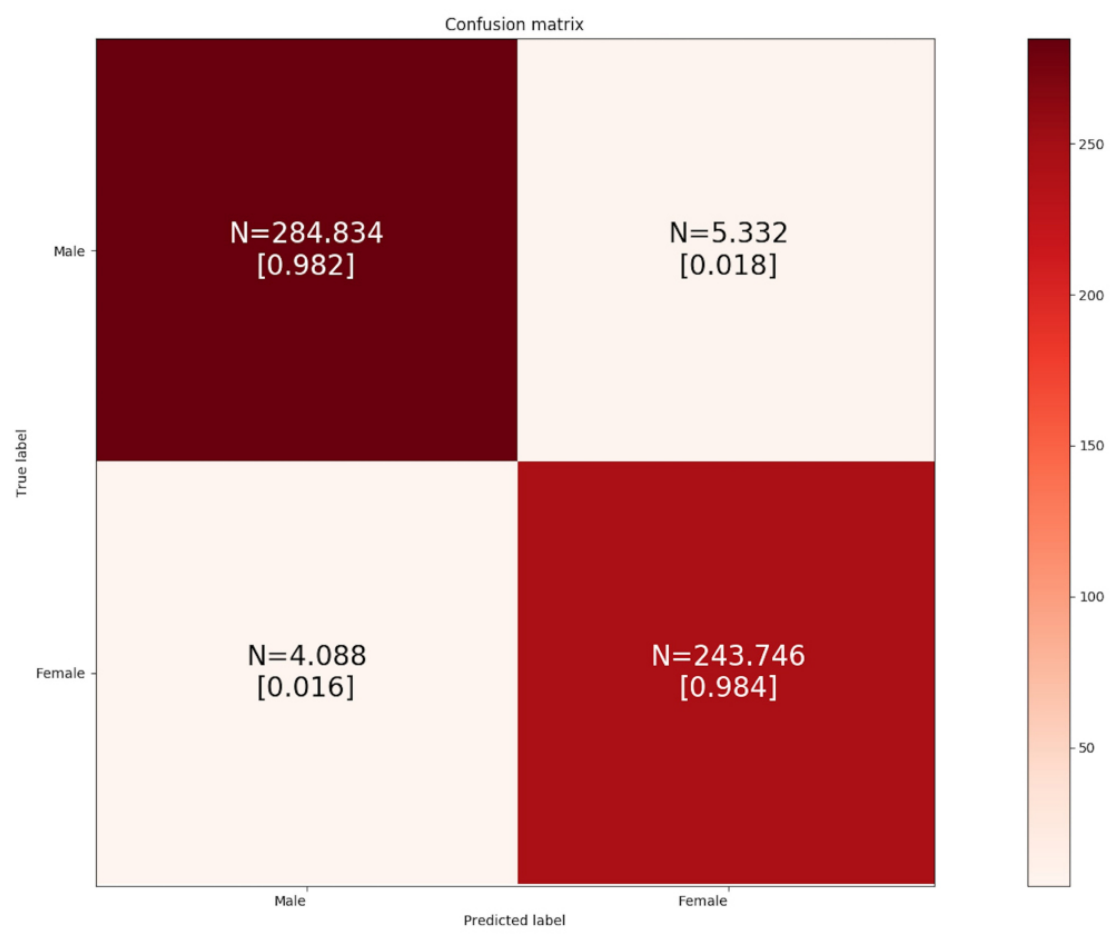

Figure 4. The confusion matrix for the test set (500 repetitions). 


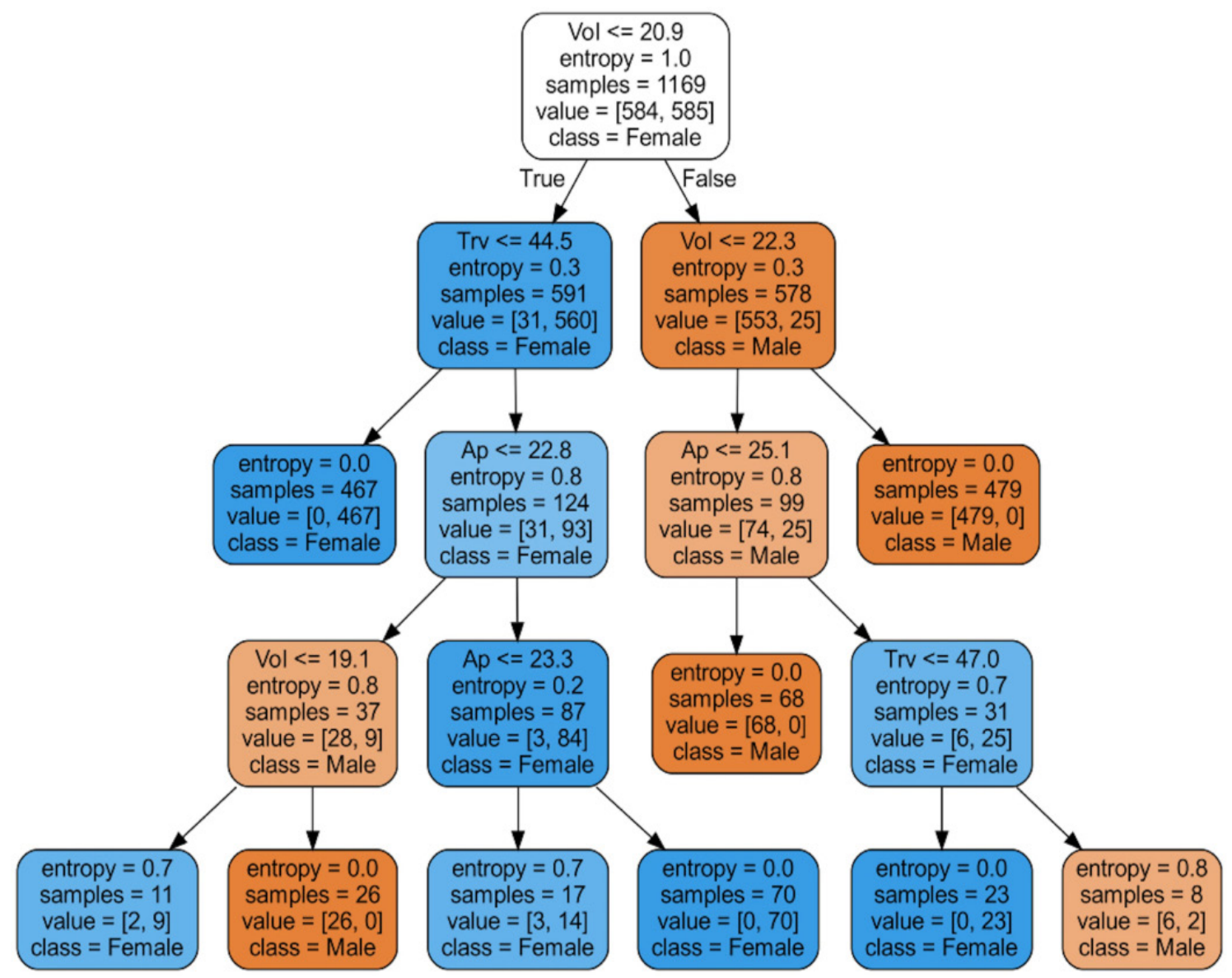

Figure 5. The rule set obtained after the DT. Ap: Anterior to Posterior length length, Trv: Transversal length, Cc: Cranio-Caudal length, Vol: Volume.

\section{DISCUSSION}

Gender determination plays an important role in the identification of human remains since it reduces the likelihood of identification (16). In forensic anthropology, it is essential to accurately define the measurement parameters. Thus, researchers using these parameters could understand the definitions and reproduce the measurements $(1,5)$. Previous studies showed that different populations have different bone characteristics, and these characteristics may affect the process of identifying sex (17-19). Since the patella is resistant to postmortem and taphonomy changes and it is generally recovered in forensic cases (1), the patellar measurement parameters were used in the present study to predict gender.

In our study, it was found that the Sen value for male patellar measurements was 0.01 percent higher when compared to the predictions conducted with female patellar measurements. On the other hand, the Spe value for the predictions determined with female measurements was calculated as 0.01 percent higher when compared to the predictions determined with male measurements. The rate of the prediction of male individuals with patellar measurements was $98.2 \%$ and the rate of the prediction of female individuals was $98.4 \%$.
Measurements conducted on most bones exhibited higher mean values for males when compared to those for females. Patellar findings have exhibited a similar pattern $(20,21)$. In the present study, it was found that patellar Ap, Trv, Cc, and Vol values were higher in males when compared to females.

In the present study, all four patellar variables demonstrated statistically significant differences based on gender. This revealed that the patella is dimorphic based on gender. Thus, discriminant function equations obtained with the variables could be used in gender determination (1). Similar findings were reported for South African white (20), South African black (22), Thai (23), Japanese (24), South Italian (25), and Medieval German (4) communities.

LDA method is one of the classically used methods for classification, and for revealing the relationship between parameters and classes, artificial neural network (ANN) are more successful. Missing, incorrect or unusually variable data are disadvantages of $\operatorname{LDA}(19,26,27)$. In contrast, DT, which is a machine learning algorithm, was used in the present study instead of LDA and ANNs for gender discrimination. DT allows forensic specialists, anthropologists, anatomists, and pathologists to make highly accurate decisions using dry bones or 
reconstructed CT images. Furthermore, a scale was produced that could help them to obtain results using a DT based on measurements conducted without a computer.

In the study conducted by Curate et al., the data obtained with femur were analyzed for measurement errors using Technical Error of Measurement, Relative Technical Error of Measurement and Coefficient of Reliability (28). LDA has been used in several studies to predict gender using bone measurements $(28,29)$. Taking advantage of this feature of the LDA, values that reduce success during gender prediction were excluded in the present study. In the literature, LDA has been used as a good outlier detector due to this property (30). In the present study, LDA was used to improve the findings due to this particular property.

The sensitivity of predictions for males was 0.01 percent higher when compared to predictions for females in gender predictions based on male and female patellar measurements. The 0.01 difference was considered insignificant since it was a very low value. The fact that Acc value for the DT general solution model run on the test set after outlier removal with LDA was quite high demonstrated that there was no difference in the prediction of gender by the constructed model based on genders.

Although it was observed that the use of high maximum depth of tree values positively affected the success, it became a disadvantage when writing the set of rules for gender prediction. Thus, models with lower maximum depths of tree were preferred. This made it easier to predict gender by following the propositions available in tree branches. Selecting the maximum depth of tree value of 4 (Figure 4) provides an advantage for the researchers by allowing them to use the branches in the tree structure and gender cut-off values without the need for a computer.

When looking at gender prediction studies from the patellar bone measurement, it appears that studies focus on that the patella is a suitable bone for gender discrimination. In this study, it was found that the accuracy score was low before the outlier data was cleared with LDA. After removed outliers values from the set was found that the accuracy score was high. Because of that, it was thought that the data removed from the study via LDA decreased the success of gender discrimination due to effects such as demographic characteristics, physical characteristics such as height and weight, body type and factors affecting the remodeling processes of the bone. On the other hand, since this study does not use physical features such as demographic data, height and weight as a model, this idea could not be tested, and accepted as a constraint.

\section{CONCLUSION}

The application of DT analysis based on patella morphometry provided a simple and adequate approach with high accuracy in gender determination. The quite high Acc value seemed to prove the exact validity of gender accuracy. Furthermore, the method allows the specialists to make highly accurate decisions using image analysis method or dry bone measurements. Furthermore, a scale based on measurements conducted without a computer but the decision tree rules were produced. Exclusion of outlier values that could reduce the success during gender prediction with LDA improved the findings of the present study.

Financial disclosures: All authors report no financial interests or potential conflicts of interest.

Conflict of Interest: The authors declare that they have no competing interest.

\section{Ethical approval}

This study was conducted in accordance with the ethical principles stated in the "Declaration of Helsinki" and permission was obtained from Ethics Committee of Karabuk Universityfor the use of patient data for publication purposes.

\section{REFERENCES}

1. Peckmann TR, Meek S, Dilkie N, et al. Determination of sex from the patella in a contemporary Spanish population. J Forensic Leg Med 2016;44:84-91.

2. Akhlaghi $M$, Sheikhazadi $A$, Naghsh $A$, et al. Identification of sex in Iranian population using patella dimensions. J Forensic Leg Med 2010;17:150-5.

3. Abdel Moneim WM, Abdel Hady RH, Abdel Maaboud RM, et al. Identification of sex depending on radiological examination of foot and patella. Am J Forensic Med Pathol 2008;29:13640.

4. Kemkes-Grottenthaler A. Sex determination by discriminant analysis: an evaluation of the reliability of patella measurements. Forensic Sci Int 2005;147:129-33.

5. Peckmann TR, Fisher B. Sex estimation from the patella in an African American population. J Forensic Leg Med 2018;54:1-7.

6. Savall $F$, Faruch-Bilfeld $M$, Dedouit $F$, et al. Metric Sex Determination of the Human Coxal Bone on a Virtual Sample using Decision Trees. J Forensic Sci 2015;60:1395-400.

7. Yong YY, Lu Y. Decision tree methods: applications for classification and prediction. Shanghai Arch Psychiatry 2015;27:130-5.

8. Welcome to Python.org [Internet]. 2019.

9. Seabold SP, J., editor Statsmodels: Econometric and Statistical Modeling with Python. PROC OF THE 9th PYTHON IN SCIENCE CONF 2010.

10. McKinney W, editor pandas: a Foundational Python Library for Data Analysis and Statistics2011.

11. Buitinck L, Louppe $G$, Blondel $M$, et al. API design for machine learning software: experiences from the scikit-learn project. arXiv preprint arXiv:13090238. 2013.

12. Pedregosa F, Varoquaux G, Gramfort A, et al. Scikit-learn: Machine learning in Python. the $\mathrm{J}$ Machine Learning Res 
$2011 ; 12: 2825-30$

13. Gomez M, De Benzo Z, Gomez C, et al. Comparison of methods for outlier detection and their effects on the classification results for a particular data base. Analytica Chimica Acta 1990;239:229-43.

14. Du PX, D. The Application of Decision Tree in Gender Classification. Congress on Image and Signal Processing Sanya, China; 2008. p. 657-60.

15. Gupta B, Rawat A, Jain A, et al. Analysis of various decision tree algorithms for classification in data mining. International J Computer Applications 2017;163:15-9.

16. Robinson MS, Bidmos MA. The skull and humerus in the determination of sex: reliability of discriminant function equations. Forensic Sci Int 2009;186:86 e1-5.

17. Puisoru M, Forna N, Fatu AM, et al. Analysis of mandibular variability in humans of different geographic areas. Ann Anat 2006;188:547-54.

18. Saini V, Srivastava $R$, Rai RK, et al. Mandibular ramus: an indicator for sex in fragmentary mandible. J Forensic Sci. 2011;56 Suppl 1:S13-6.

19. Turan $M K$, Oner $Z$, Secgin $Y$, et al. A trial on artificial neural networks in predicting sex through bone length measurements on the first and fifth phalanges and metatarsals. Comput Biol Med 2019;115:103490.

20. Bidmos MA, Steinberg N, Kuykendall KL. Patella measurements of South African whites as sex assessors. Homo 2005;56:69-74.

21. Steyn M, Iscan MY. Osteometric variation in the humerus: sexual dimorphism in South Africans. Forensic Sci Int 1999;106:77-85.
22. Dayal MR, Bidmos MA. Discriminating sex in South African blacks using patella dimensions. J Forensic Sci 2005;50:1294-7.

23. Phoophalee $P$, Prasitwattanaseree $S$, Riengrojpitak $S$, Mahakkanukrauh $P$, editors. Sex determination by patella measurements in Thais. Proceedings of 1st Asean Plus Three Graduate Research Congress, Chiang Mai; 2012.

24. Sakaue K. New Method for Diagnosis of the Sex and Ageat-death of an Adult Human Skeleton from the Patella. Bull Natl Mus Nat Sci, Ser D, 2008. p. 43-51.

25. Introna FJ, Di Vella G, Campobasso CP. Sex determination by discriminant analysis of patella measurements. Forensic Sci Int 1998;95:39-45.

26. du Jardin P, Ponsaille J, Alunni-Perret V, et al. A comparison between neural network and other metric methods to determine sex from the upper femur in a modern French population. Forensic Sci Int 2009;192:127 e1-6.

27. Mahfouz M, Badawi A, Merkl B, et al. Patella sex determination by 3D statistical shape models and nonlinear classifiers. Forensic Sci Int 2007;173:161-70.

28. Curate F, Albuquerque A, Ferreira I, et al. Sex estimation with the total area of the proximal femur: A densitometric approach. Forensic Sci Int. 2017;275:110-6.

29. Kruger GC, L'Abbe EN, Stull KE. Sex estimation from the long bones of modern South Africans. Int J Legal Med 2017;131:275-85.

30. Nguyen HV, Gopalkrishnan V, editors. Feature extraction for outlier detection in high-dimensional spaces. Feature Selection in Data Mining; 2010. 